\title{
Changing behavior - ensuring hand hygiene is an institutional priority
}

\author{
J Bradford ${ }^{1 *}$, J Brett ${ }^{1}$, A Bull ${ }^{1}$, B Kennedy ${ }^{2}$, S Borrell ${ }^{2}$, A McMillan² $^{2}$, M Richards ${ }^{1}$ \\ From International Conference on Prevention \& Infection Control (ICPIC 2011) \\ Geneva, Switzerland. 29 June - 2 July 2011
}

\section{Introduction / objectives}

In 2004 the Victorian Quality Council developed a statewide model aiming to improve hand hygiene and reduce healthcare associated infections across Victoria. Many aspects of this culture change program have been incorporated into the National Hand Hygiene Initiative which commenced in 2008.

\section{Methods}

All 86 acute public Health Services in Victoria were funded to participate and submit three hand hygiene compliance audits per year. Education, resources and auditor training was provided. Healthcare worker hand hygiene compliance was assessed by direct observation using a tool based on the WHO 5 Moments.

In 2009 an organisational hand hygiene compliance benchmark was included in the Health Service Performance Management Framework of the Department of Health. Health Service Chief Executive Officers (CEO) were provided quarterly feedback as to their performance against the agreed benchmark, this performance was also made known between organisations.

\section{Results}

Health Services have progressively improved compliance and most recently $95 \%$ achieved the current benchmark of $65 \%$. Feedback from Infection Control Consultants has also been positive, reporting a marked increase in executive support for the hand hygiene initiative.

\section{Conclusion}

The successful implementation and sustainability of any hand hygiene initiative requires leadership from all levels including government, health service CEO, and ownership of the program by individual clinical areas and

${ }^{1}$ VICNISS Coordinating Centre, Melbourne, Australia

Full list of author information is available at the end of the article clinicians. Hand hygiene compliance as a performance indicator promotes executive commitment to the program and ensures hand hygiene is an institutional priority.

\section{Disclosure of interest}

None declared.

\section{Author details}

${ }^{1}$ VICNISS Coordinating Centre, Melbourne, Australia. ${ }^{2}$ Quality, Safety and

Patient Experience, Department of Health, Victoria, Australia.

Published: 29 June 2011

doi:10.1186/1753-6561-5-S6-P111

Cite this article as: Bradford et al:: Changing behavior - ensuring hand hygiene is an institutional priority. BMC Proceedings 2011 5(Suppl 6):P111.
Submit your next manuscript to BioMed Central and take full advantage of:

- Convenient online submission

- Thorough peer review

- No space constraints or color figure charges

- Immediate publication on acceptance

- Inclusion in PubMed, CAS, Scopus and Google Scholar

- Research which is freely available for redistribution 